\title{
A Brief Analysis on the Chinese Influence of the Nordic Chair Furniture
}

\author{
Jing Zeng, Lei Wang \\ College of Forestry, Sichuan Agricultural University, Wenjiang 611130, China
}

Keywords: Nordic furniture; market development; furniture Sinicization

\begin{abstract}
By exploring the chair furniture design of Scandinavia countries located in Nordic Europe, an analysis of modern furniture and human touch is conducted to understand the importance of local traditional wood for humanized innovation design. "The chair design is the beginning of any interior design," said Finland design master Tapiovaara. The chair is the most expressive variety of art. With the increasingly frequent exchanges at home and abroad, the rapid development of economy has led to the flow of design, thus the furniture of Nordic Europe occupy a large part of China's furniture market in recent years. Under the influence of all sides, the localization furniture design has been innovated. Therefore, the development and extension of Nordic furniture in China is an innovation point for Chinese furniture design, and a new starting point for seating furniture to rediscover vitality.
\end{abstract}

\section{Nordic chair furniture developed in China}

Guangdong Furniture Fair every March are very concerned about the industry, it is not difficult to find in the furniture exhibition, furniture into the new trend, its development trend is rising and diversification. Many large furniture enterprises have launched a series of Nordic style furniture, and strive to find the opportunity to develop themselves in this trend. In the twentieth Century, with the continuous development of modern industry, Nordic designers combined traditional handwork and industrialization to form a more humanized design style that accords with the needs of consumers. The integration of modern design makes the Nordic style furniture more in line with the international market demand, and is more and more loved by consumers. Especially under the impetus of the new 1generation of young people's aesthetic appreciation, its furniture proportion has increased sharply in China, and demand has increased rapidly.

As is known to all, the Nordic countries are rich and rich. The gap between the rich and the poor is not large among the five countries. The middle class is a common consumer group. Coupled with their perfect social welfare system, these lifestyles reflect the state of being peaceful and rich, showing the public's aesthetic tendency. With the rapid development of China's social economy in recent years, the number of middle and upper level consumer groups is increasing, and the consumption concept is constantly changing by foreign influence, seeking a more comfortable sense of home. Nordic furniture is in line with the needs of the current domestic consumers, and its pursuit of natural simplicity and the concept of social sustainable development is an important factor in its popularity in China.

With the impetus of globalization, the economic and cultural exchanges between countries are becoming increasingly close. Many home brands in northern Europe have been in China, opening the furniture market in China, and also affecting the design direction of China's furniture. In order to get broader development, Nordic designers continue to innovate, strive for breakthroughs in technology and material performance, and let people experience better home design. Nordic has a large number of home brands, and IKEA, created in 1943, is a household name for the Swedish brand. At the same time, it takes into account the functions of simplicity, grasping the needs of the core, and thus achieving a high level of simplicity. It is this simple and simple design that makes it a world famous.

MUUTO is a famous Danish home brand, founded in 2006. Although the establishment of time is not long, but MUUTO has been a well-known international furniture brand. It adheres to the core idea of "design comes from human nature", based on the quiet and concise traditional Nordic 
Europe, and adds lots of coloring furniture to match, so that the original Nordic furniture with some cool meaning is endowed with a little warmth while being kept simple. Its chair furniture emphasizes the integration of technology and materials, and constantly achieves another new height on the basis of existing ones. It also takes into consideration the consistent simplicity, simplicity and natural design concept, which is full of individuality and maintains the traditional design in northern Europe. ${ }^{[1]}$ is the most famous product of the seat class, which is the nerd chair. This chair is a typical representative of modern Scandinavia traditional design. Seamless integration between backrest and seat is its most unique design. The whole chair has smooth lines and comfortable aesthetic feeling. The use of this small chair is very high. The design of its colorful colors and human comfort is very popular. Though there are many imitation models in China, it is also dwarfed.

Another brand is HAY, compared with IKEA most of its products in the selection of the color are more sprightly, relatively low purity, more warmth, let the indoor display better with white and color collocation use logs. In the domestic market, the Nordic style is centered on young people. They are mostly small family. If we want to enhance the room texture, HAY is a good choice. Its product line is simple and changeable, and the price is not very expensive. Compared with MUUTO, they have similar styles, but there are still obvious differences. MUUTO will be better in texture, but for most of the domestic consumption level, it will be slightly more expensive. So in a comprehensive way, HAY is more widely used.

With HAY as the main representative, its seat design is always trying a variety of new technologies and materials, and it also maps its development prospects and strength. On the wooden seat, it uses the bending process of multilayer board processing and multilayer board; the metal seat with specular metal or brass processing, and other innovative use of materials, such as cork technology, surface coating, linoleum polyethylene plastic injection molding process, felt hot forming process, which all reflect the innovation in brand design in it, continue to try new technology, constantly increase exploration team of designers and material and technology research and development efforts, trying to do better. In the Nordic style furniture, do not want to let the consumer stampede in, aesthetic fatigue, in many furniture talent shows itself, we must continue to innovate, grasp the consumption trends in the development of history, location, present and future find themselves in the mining, never stop the feasible development, taking into account their own unique ingredients. This should be seen from two aspects of space and time, that is, there should be a global pattern and vision in space, and a historical height in time. ${ }^{[2]}$

\section{Recent situation of chair furniture in China}

China's furniture has gradually recovered since 1980s. It has completed the process of industrialization in just more than 20 years. It has entered the industrial mass production from manual workshops. Now, China has become a large furniture manufacturing country and a big exporter, and has initially formed a furniture industry system with Chinese characteristics. But in the innovation of furniture design, Chinese furniture industry especially the design level of imitation novelty style, fashion, their relatively less innovation, form and function is dull, the quality level is not high, low quality and low price competition is not complete, especially hinder the sustained development of the furniture industry. There are few furniture brand products, low value-added products, lack of high level and creative furniture designers, less original furniture design, plagiarism is very serious. It is difficult for Chinese furniture to continue to develop a better state of development by the pressure of on the one layer and one layer. ${ }^{[3]}$ The design of this piece of furniture in the seat, mainly presents two major problems: one is the material utilization gap is too large, or build expensive, rare wood to high-end seats, regardless of the applicability of the public, the product is difficult to expand the market. Either the design with inferior wood for the seats, the blind pursuit of low cost to obtain high profits without considering the nature of the product, is designed to create a better life experience. At the same time, it is worth noting that the design works also have commercial value, which can bring rich rewards to the enterprise, that is, the perfect combination of art and utilitarianism. The two is the monotonous reproduction of the modeling. In 
China seat furniture, most enterprises are lack of professional designers for product planning, development and design. They do not pay enough attention to the core design role of designers, blindly follow the trend and do not dig their own feasible points. Now the Chinese furniture market is very short of professional design talents, and the reserve is insufficient and the quality is not high. The threshold of interior furniture design is relatively low. No matter what the foundation is, they want to invest in this direction, lack of time and experience enrichment and quality improvement. All these reasons lead to shortage of talents in furniture market. The design of seat furniture is more comprehensive. It requires not only familiarity with material usage and technology making, but also a high aesthetic standard. It has its own artistic perspective and learns to design products creatively. At present, the entry of Nordic furniture brings a new starting point for domestic design. We should learn from the essence of it effectively instead of bulk copying blindly, and find the key points suitable for its long-term development.

\section{North European chair furniture in China}

The most successful example of applying the traditional Chinese style to the Nordic seat class is Hans Wagner, the master of the world's Danish furniture design. He created more than more than 500 pieces of chairs in his life and created many classic works. Although Wagner's work with the Nordic cold clean atmosphere, but in the design of the most famous works of traditional furniture, Chinese especially the transmission element of Ming furniture reflected obviously. ${ }^{[4]}$

Wagner was infatuated with Chinese furniture in the early days, and the inspiration from Oriental furniture was obvious in his personal style. The most famous one is The Chinese Chair, which was inspired by the design of the Ming Dynasty chair in China in 1943. It is said that he was inspired by the Chinese chair in the Danish Museum of technology. The chair looks like a simplified version of the Ming style chair, half round back and arm connected to the backboard is attached to the back curve of the body, the leg part is composed of four pin Cheng contain each other, ensure a steady solid chair. The second is the "Y- chair" (W ishbone Chair), the chair is to help the traditional crafts China circle as the prototype, under Wagner's ingenious design of organic curves Nordic into which the visual beauty brings radian impact, while the tactility and comfort of strive for further improvement. Wagner once said, "The body of a man will never be still, not in peace." A good chair should be able to allow people to adjust their posture freely on it and keep the blood flowing for a long time. Back by "Y" type, to abandon the traditional Chinese back heavy feeling, cleverly into the organic structure, the beauty of form image and man-machine function combination, let the heavy Chinese chair suddenly becomes lightsome and clever, fashion and personality, convincing. The Y backplane can be reasonably supported by human body, hind foot part up directly with an arc of a brain connected, and bend forward, to the Ming style chairs in "federal role stick". In [3] he designed chairs, fully combine the artistic and practical perfect design led to a new starting point, it is not only a breakthrough innovation of furniture design, is also extremely important to learn from the design concept for Chinese local furniture development.

Nordic furniture has become a market trend clearly from the beginning of 2016. By the second half of 2016, it became an extremely important direction for the development of the furniture market. Nordic furniture at that time was very heavy in northern Europe, some called it "tunnel", but the strong sense of alien sense appeared to be discomforting. After all, in China earth, it is difficult to make China ordinary consumers can accept such a heavy taste of Nordic furniture design. At that time, a company made clear the grafting of Nordic furniture and Chinese furniture. By now, to observe the Nordic furniture, almost most of the Nordic furniture looks comfortable and friendly. The basic elements of Nordic furniture are still there, but the elements of Chinese furniture are obviously implanted. This Sinicization of Chinese furniture has overwhelming advantages in the market. Especially in the furniture of the seat class, the Chinese people have a special preference to the solid wood material and are also on the body. The more the body is, the more it has the sense of value, and it also shows a kind of identity and status. It is this special sentiment that leads to the change in the design of the Nordic style in the Chinese market. The designers on the basis of these factors, the product will do as the Romans do, from the material process and appearance made a 
breakthrough, the acceptability greatly expanded. The whole is rounded and slightly heavy, which can be said to be the native development of the Nordic furniture in China. For example, to wood. Luxuries a chair, it absorbed the Nordic brand Carl Hansen \& Son styling inspiration, and adds the pieces back in place, slender and replaced by sturdy wood before, give a person visual sense stocky heavy, this is more in line with Chinese aesthetic. From Nordic wind to Chinese Nordic wind, it continued the simplicity, humanity and nature of furniture in northern Europe, and also melted into the taste and habits of Chinese Orientals, which made most of the consumers in China have a new way of life for the change of household needs.

Taking all factors, the Nordic style furniture products will become the mainstream industry, light luxury, fashion, personalized demand will still exist, in order to meet the needs of different users and the development trend of the industry, furniture enterprises, R \& D and production enterprises in the wardrobe products and develop marketing plans to take the initiative to master the industry mainstream style and mainstream material, price the wind, only in this way, in order to precise positioning and direction to win the market. ${ }^{[5]}$ Furniture design, in itself, is designed for a better way of life, and this is the original purpose of the design. In order to reach the location that most people can touch, we need to make progress based on the aesthetic needs of consumers, and constantly strive for new products, so as to promote the development of the whole furniture design.

In recent years, with the development of Chinese furniture in a younger and simpler way, Scandinavia furniture has sprawled in various exhibitions and markets, and has become a new trend. Indeed, the Nordic furniture design enjoys a high reputation in the world, leading the trend of the world's furniture design. In the current of the Nordic wind, we must learn to learn from it if you want to develop. Nowadays, the phenomenon of homogeneity of products is serious, which makes it difficult for many enterprises to carry out better operation and development. Therefore, we have to learn to dig out the suitable part of the Nordic design concept, and then join its own unique element culture to form a personal brand. In China, some worth mentioning is the system and have independent beauty brand, is the Vatican, cabinetmakers, lost and found.

The Vatican few as the representative, is taking the clean design route is more Zen. It should be said that he has slowly stepped out of this homogeneity and found its own brand of temperament. A few furniture design features is on the line of special study, obviously example is that almost all of the Vatican a few furniture feet are awl shape, soft lines. The design of Van Gogh has used a large number of corners and radians. When the hardwood furniture is processed, the arc and the round angle are more than the right angle. But because of this arc, Vatican furniture of some of the more recent metaphysics of Zen. The style is quiet and gentle, which is mainly on the line. It is mixed with Japanese and classical Chinese, and finds a place of its own. Wang Shixiang, a famous cultural and cultural expert, said: "wooden furniture is an indispensable thing in life." We think that one should sit on a chair every day, work on the table, sleep on the bed, and at least 3/4 of the time to deal with the furniture. The design of new furniture, in addition to the demand for economic and durable, it is necessary to pay attention to the practical beauty. "It can be seen that in addition to comfort, beauty is still one of the most important attributes of furniture.

Taking all factors, the Nordic style furniture products in the future will become the mainstream industry, light luxury, individual demand still exists, in order to meet the needs of different users and the development trend of the industry, furniture enterprises to drive industry and to grasp the mainstream style, material price in product research and development production and marketing plan, so in order to get the precise positioning and direction in order to win the market. ${ }^{[6]}$ grasps the main thread in the change of the environment and doesn't lose itself. In the trend of development, we must grasp the key points and innovate, so that we will go far in the future.

\section{Summary}

With the globalization of economy, the implementation of China's series of open policies and the decline of furniture tariffs, the international furniture industry will gradually enter and influence the Chinese furniture industry, bringing the dual influence to China. From a positive point of view, the increasing number of imported furniture, the improvement of product quality and the continuous 
expansion of domestic and foreign market will make domestic furniture enterprises get more effective information about design, technology, and technology and so on. People-oriented, function orientation, diversification of the use of materials, in accordance with the requirements of natural expression is the main morphological characteristics of Nordic furniture, Denmark, Finland, Norway, Sweden and other Nordic countries, the designers will combine the "international style" and the design concept of local perfect, create a Nordic design a profound impact on human's school. Now, in China, through the in-depth study of Nordic design and the local analysis of Chinese furniture design, it also hopes to explore a way for China's furniture enterprises to develop uniquely. Chair furniture has always been the core performance of home design; its comprehensive expression is strong and intuitive, testing the level of the designer. The popularity of Nordic style requires designers to have unique concerns to innovate modern design and achieve the perfect combination of functionality and aesthetics in the trend.

\section{Acknowledgements}

Key Laboratory of Wood Industry and Furniture Engineering of Sichuan Provincial Colleges and Universities

\section{References}

[1] Ju Xiaoling. The characteristic advantage and influence of furniture design style of Nordic Europe [J]. Journal of Weifang Institute of education, 2001, 18 (1): 79.

[2] Li Yongqing, Liu Wenzhi. The present situation, problems and suggestions of China's furniture industry [J]. Forestry industry, 1999, 17 (1): 11-13.

[3] Wang Yi Jing. Danish furniture design masters Hans. Wiener [J]. Wuxi Nanyang College Journal, 2007, 12 (1): 60-61.

[4] Xu Baiming. China contemporary furniture design where the Jiangsu [A]. Nanjing: Nanjing Forestry University, 2017:14.

[5] Zhao Junbo, Li Bao potential. The prospect of China's furniture industry [J]. Forestry industry, 1999, 43 (2): 10-13. 